\title{
Corpos aliadxs e lutas políticas em tempos de regimes de exceção
}

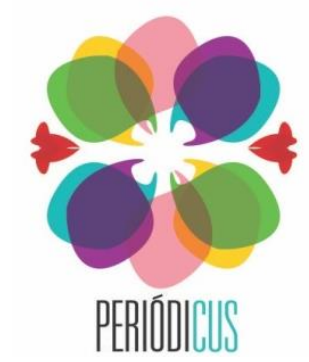

ISSN: 2350-0844

ก. II, v. 1 mai. -out. 2019 р. 미-प4.

\author{
Elias Ferreira Veras ${ }^{1}$ \\ Kleber Simões ${ }^{2}$
}

Durval Muniz de Albuquerque Junior ${ }^{3}$

RESUMO: Inspirado por Judith Butler, Michel Foucault, Giorgio Agamben, Paul B. Preciado, Angela Davis, Jasbir Puar, Achille Mbembe, Lélia Gonzalez, dentre outrxs, o presente dossiê problematiza como se articularam/articulam sexualidade, gênero e política nos contextos históricos (brasileiro e internacional) marcados pelos regimes de exceção. Corpos-vivos; corpos-mortos; Corpos alijadxs; corpos aliadxs; Corpos em luto; Corpos em luta.

Em 2018 foi lançado no Brasil o livro Corpos em aliança e a política das ruas - notas para uma teoria performativa de assembleia (Ed. Civilização Brasileira), de Judith Butler. As reflexões presentes na obra sobre a política de gênero e o direito de aparecer, os corpos em alianças e a política das ruas, a vida precária e a ética da convivência, a vulnerabilidade corporal e a política de coligação, dentre outras, inspiraram a proposta deste dossiê.

Em diálogo com Butler, mas também com Michel Foucault, Giorgio Agamben, Paul B. Preciado, Ângela Davis, Jasmin Puar, Achille Mbembe, Lélia Gonzalez, dentre outrxs, nos questionamos: como se articularam/articulam sexualidade, gênero e política nos contextos históricos (brasileiro e internacional) marcados pelos regimes de exceção? Interessou-nos cartografar essas articulações através das lutas dos corpos aliadxs na construção e manutenção da democracia. Quais resistências se inscreveram/inscrevem nesses corpos-políticos? Quais discursos foram/são produzidos? Quais tecnologias foram/são mobilizadas? Quais redes de pode-resistência foram/são tecidas? Corpos anormais-estigmatizados-abjetos-queer (r)existindo nas ruas, nas redes, nas artes, na política (in)escrita nos/dos corpos em aliança.

\footnotetext{
${ }^{1}$ Professor da Universidade Federal de Alagoas (UFAL), coordenador do Grupo de Estudos e Pesquisas em História, Gênero e Sexualidade (GEPHGS/UFAL). E-mail: eliashistoria@yahoo.com.br

${ }^{2}$ Professor da Universidade do Estado da Bahia (UNEB) e integrante do Núcleo de Pesquisa e Extensão em Culturas, Gêneros e Sexualidades (NuCuS), da Universidade Federal da Bahia. E-mail: simoes_kleber@yahoo.com.br

${ }^{3}$ Professor da Universidade Estadual da Paraíba (UEPB). E-mail: durvalaljr@gmail.com
} 
A afectação que deu origem à proposta do presente dossiê, contudo, não foi provocada somente pelo encontro com a performatividade escrito-política de Butler, mas, sobretudo, pelo contexto que vivíamos em 2018. Estávamos (e continuamos) afetados pelo golpe sofrido por Dilma Rousseff, em 2016; pela execução de Marielle Franco e de Anderson Gomes, em março de 2018; pela prisão de Lula, um mês depois, fato que o impossibilitou de concorrer à presidência da República; pelo avanço da política de ultradireita e seu discurso de ódio às mulheres, negros/as e LGBT+ na campanha presidencial daquele ano. De muitos modos, esses acontecimentos, que se prolongaram em 2019 através de políticas neoliberais que tornaram a vida de mulheres, homens, jovens, negros, negras, pobres e LGBT+ mais vulneráveis e precarizadas, atravessaram nossa proposta inicial, reverberando nos textos que compõe este dossiê.

Em Alianças monstruosas e desejantes contra o sequestro da política pela esfera estatal, Marcelo de Trói investe nas questões que envolvem representação, arte e ativismo para pensar outras formas de política e regimes de alianças diante da radicalização do campo da extrema direita no Brasil. Com base nas teorias pós-humanas, o autor localiza o corpo dissidente como abertura para alianças monstruosas e desejantes.

No artigo Generificação multisseccional ou racialismo multissegmentário, Yuri Bataglia Espósito analisa como os regimes de dominação interseccional produzem e naturalizam a diferenciação social através de dispositivos político-discursivos. Articulando estudos pós-estruturalistas e queer com obras que estudam o racismo, a racialização e a colonialidade, Espósito afirma que dispositivos de subjetivação precarizante prejudicam corpos e populações, orientando-se por códigos ordenadores sociais hegemonizados pelos regimes de dominação.

Clara Eliana Cuevas aborda, em Crime, sexualidade e opinião pública: o caso 108 y quemado em Assunção, 1959, como a homossexualidade foi reprimida durante a ditadura paraguaia. A partir do assassinato de Bernardo Aranda, locutor da Rádio Comuneros, a autora revela como uma grande onda de perseguição contra homossexuais levou à prisão mais de uma centena de pessoas acusadas de "duvidosa conduta moral".

Por sua vez, no artigo Alianzas y agencias políticas de la disidencia sexual y de género: ¿Una forma para sobrevivir en El Salvador? Amaral Arévalo e Andre Solorzano analisam os processos de alianças e agências políticas como estratégias de sobrevivência, resistência e humanização da população LGBTI+ no contexto de violência epidêmica e crônica sofrida por El Salvador. Os autores apontam que

Periódicus, Salvador, n.11, v. 1, mai-out.2019 - Revista de estudos indisciplinares em gêneros e sexualidades Publicação periódica vinculada ao Núcleo de Pesquisa NuCuS, da Universidade Federal da Bahia - UFBA ISSN: 2358-0844 - Endereço: http://www.portalseer.ufba.br/index.php/revistaperiodicus 
os processos de reconhecimento são limitados e precários, na medida em que foram assumidos como uma política personalizada e não institucional.

Retornamos ao cenário brasileiro através do texto 2019: a revolução dos vírus ou Uma odisseia no espaço brasileiro, de Ramon Fontes. Nele, Ramon reflete sobre como o vírus da imunodeficiência humana (hiv) ou a classe geral dos vírus podem ser acionadas em prol da construção de uma política de reação subjetiva contra as violências de gênero advindas do pensamento colonial e heteronormativo no território brasileiro.

Pedro Farias Mentor, em Representação, metafisica da substância e poder em Judith Butler, toma como ponto de partida o pensamento da filósofa americana para refletir sobre o conceito-prática de representação política e demonstrar a relação desses conhecimentos com as categorias de sujeito, política, ontologia, cultura e sexualidade.

No artigo Corpos aliados em regime de precariedade: cartografias do desencantamento nas dissidências sexuais e de gênero nos Reisados em Juazeiro do Norte-CE, Ribamar José de Oliveira Junior e Lore Fortes articulam sexualidade, gênero e política no contexto da dança de Reisado na região do Cariri cearense. Teoria performativa da assembleia, processos de experimentação nas micropolíticas de gênero são alguns dos caminhos teórico-metodológicos percorridos pelos autores para refletir sobre a dança de Reisado como uma forma de performatividade corporificada plural.

Performances trans incomodam? Quando a vida em público é passível de violência, de Daniela Souza, problematiza, a partir da novela $A$ força do querer, da Rede Globo de Televisão, as performatividades discursivas midiáticas que narram as lutas de corpos marginalizados, excluídos e desumanizados. De acordo com a autora, a visibilidade midiática da violência contra o corpo trans confere a esse subgrupo de vidas, marginalizado pelo biopoder, o reconhecimento da precariedade. Ao mesmo tempo, o afeto torna o corpo trans reconhecível, dá vida a esse corpo, humaniza-o, torna-o enlutado.

No artigo "Ser bicha é um estado de espírito, de choque, de sitio, de graça”": a poesia-bicha de Paulo Augusto, João Victtor Gomes Varjão analisa a bicha nas poesias de Falo, de Paulo Augusto (2003). Foucault, Preciado e Zamboni são convocados por Varjão para conceber a bicha como um sujeito desviante dos dispositivos, configurando seu pensamento bicha.

$\mathrm{O}$ artigo Quando a pedagogia toma posição ou o que aprendemos diante das imagens dos homens do triângulo rosa?, de Gregory da Silva Balthazar, problematiza o lugar da imagem na 
construção de uma pedagogia que nos provoca a criar linhas de resistência. A partir da análise do filme Bent, de Sean Mathias (1997), Balthazar analisa o lugar das imagens na luta pela memória das dores dos homens do triângulo rosa e, como destaca o autor, inseparável disso, o "gesto ético que estas imagens nos demandam assumir hoje".

O cinema como criador de próteses: uma análise díldica de Os rapazes das calçadas, de Eugênio Helyantus Stumm e Amadeu De Oliveira Weinmann, analisam o filme brasileiro Os rapazes das calçadas (1981) produzido no contexto da ditadura civil-militar brasileira. Para tal, os autores estabelecem diálogos entre psicanálise, arte e filosofia, deslocando a análise fílmica em diálogo com Paul B. Preciado.

Helen Barbosa dos Santos, em Homens e violência urbana: tecnologias de poder nos serviços de emergência de saúde investiga o acesso de homens aos serviços de emergência de saúde por agravos produzidos pela violência urbana. No contexto brasileiro marcado pela alta mortalidade de homens negros, pobres e jovens, a etnografia lança luz sobre os mecanismos de criminalização e medicalização que agem sobre determinados corpos masculinos.

Finalizamos o dossiê com o artigo de Renata Porcellis, Em tempos de mordaça, corpos dissidentes rompem o silêncio da máquina-escola. O texto é resultado da rede de corpos-resistência criada em torno das ações desenvolvidas em 2018 no Instituto Federal de Educação, Ciência e Tecnologia Sul-rio-grandense - IFSul - campus Pelotas - após a reinauguração do Núcleo de Gênero e Diversidade - Nuged.

Não estamos sozinhxs. Os artigos selecionados para compor o dossiê, assim como as dezenas de propostas enviadas durante nossa chamada pública - algumas delas foram redirecionadas para futuras edições da Periódicus - indicam que não estamos sozinhxs. Corpos em aliança, políticas das ruas, mas também políticas da escrita. Performatividade que não se limita a dizer, mas que se faz no dizer. Fazer-dizer-si-nos-no corpo; Dizer-fazer-se-nos-na política.

Agradecemos aos/as autores/as por terem enviados suas propostas, acreditando nesse espaço com assembleia possível de resistência e luta. Somos gratos também ao Leandro Colling e à equipe da revista Periódicus, pelo espaço e diálogo; finalmente, agradecemos cada leitor, leitora, leitxr, por fazer da leitura desse dossiê uma prática política de resistência contra todo regime de exceção.

Maceió, Salvador, Guarabira, Brasil, 10 de novembro de 2019. 